\title{
OS FATORES COMPETITIVOS DAS INDÚSTRIAS DE PEDRAS PRECIOSAS: UM MULTICASO NO INTERIOR DO RIO GRANDE DO SUL
}

\section{THE COMPETITIVE FACTORS OF GEMSTONES INDUSTRIES: A MULTICASE IN THE INTERIOR OF RIO GRANDE DO SUL}

\author{
Juliano Nunes Alves \\ Universidade de Cruz Alta - RS - Brasil \\ Josiane Lamaison de Moraes \\ Universidade de Cruz Alta - RS - Brasil \\ Denise Rossato Quatrin \\ Universidade Federal de Santa Maria - RS - Brasil
}

\begin{abstract}
Resumo: Observa-se que, para as organizações manterem-se competitivas, é necessário que conheçam os fatores internos e externos existentes no setor global e setorial, conquistando informações que thes possibilitem formular estratégias para se sustentar no mercado altamente competitivo. Visualizando essa necessidade, o presente trabalho expõe o estudo dos fatores empresariais, estruturais e sistêmicos de empresas industriais pertencentes ao setor de pedras preciosas de Salto do Jacuí - RS. Foram entrevistadas empresas desse setor com o objetivo de verificar e descrever os fatores de influência na competitividade, a partir da opinião dos seus gestores, segundo o modelo desenvolvido por Coutinho e Ferraz (1995) e Ferraz, Kupfer e Haguenauer (1995). O método utilizado para o desenvolvimento do presente trabalho foi de cunho qualitativo-descritivo, com um enfoque em um estudo de multicasos. A coleta de dados foi feita através de entrevistas semiestruturadas, em que os gestores responderam de acordo com o seu entendimento, sua opinião e seu conhecimento sobre o assunto questionado. A análise dos dados coletados foi realizada individualmente através da análise de conteúdo. Com base nos resultados obtidos, pode-se verificar que, dentre os fatores de competitividade, o que exerce maior influência nas empresas industriais pertencentes ao setor de pedras preciosas é o fator sistêmico.
\end{abstract}

Palavras-chave: setor de pedras preciosas; competitividade; fator sistêmico.

Abstract: It is observed that for organizations remain competitive it is necessary to know the internal and external factors existing in global and industry sector, gaining information that enable them to formulate strategies to sustain in the highly competitive market. Viewing this need, this paper presents the study of business, structural and systemic factors of industrial enterprises belonging to the precious stones sector of Salto do Jacuí - RS. It was interviewed companies in this sector with the objective of verify and describe the factors that influence competitiveness, through the opinion of their managers, according to the model developed by Coutinho and Ferraz (1995) and Ferraz, Kupfer and Haguenauer (1995). The method used for the development of this study was qualitative and descriptive, with a focus on a multi-case study. Data collection was done through semi-structured interviews, in which managers responded according to their understanding, belief and knowledge on the subject questioned. The analysis of data collected was performed individually by content analysis. Based on the results obtained, it could be noted that among the factors of competitiveness, which exerts a greater influence on industrial companies belonging to the gemstone sector is the systematic factor.

Keywords: gemstone sector; competitiveness; systemic factor. 


\section{Introdução}

A busca contínua das organizações por competitividade acarreta setores cada vez mais concorrentes. Com isso, os gestores devem ter a habilidade de analisar o ambiente onde a organização está inserida. Conforme Ferraz, Kupfer e Haguenauer (1995), competitividade é definida como a capacidade do gestor empresarial em formular e implementar estratégias que proporcionem à empresa aumentar ou manter, de maneira duradoura, uma posição sustentável no mercado.

De acordo com Coutinho e Ferraz (1995), o sucesso competitivo de uma organização depende da avaliação do ambiente e do conhecimento de seus adversários. Em função disso, o problema do presente trabalho é: "Quais são os fatores empresariais, estruturais e sistêmicos que afetam a competitividade do setor em estudo?", tendo como relevância a verificação dos fatores que possibilitam aos gestores analisar as estratégias adotadas pela empresa e, por meio dessa verificação, complementá-las.

Abordam-se, como tema do presente trabalho, os fatores da competitividade em empresas do município de Salto do Jacuí - RS, referência por possuir uma das maiores jazidas de pedras ágatas do mundo. $O$ trabalho tem como principal objetivo verificar e descrever os fatores de influência na competitividade em empresas industriais pertencentes ao setor de pedras preciosas do município, a partir da compreensão dos seus gestores, segundo o modelo desenvolvido pelos autores Coutinho e Ferraz (1995) e Ferraz, Kupfer e Haguenauer (1995).

O presente trabalho está organizado em seis seções. A primeira apresenta uma introdução do estudo. Já a segunda aborda o referencial teórico de modelos para análise da competitividade por meio de diversos autores. Na terceira seção, é apresentada a metodologia utilizada, sendo, na quarta seção caracterizadas as empresas do setor em estudo. Na quinta seção são explanadas as análises e os resultados. E, por fim, na sexta seção apontam-se as considerações finais, bem como sugestões para trabalhos futuros.

\section{Fundamentação Teórica}

\subsection{Modelos para a análise da competitividade}

As constantes mudanças que afetam as organizações tornam indispensável a avaliação do desempenho das empresas em relação às forças competitivas do mercado, observando a maneira competitiva no setor em que se atua. O modelo de Porter (1986) traz duas questões centrais para determinar estratégias competitivas, que são, respectivamente: como determinar a atratividade de um segmento de negócio, que pode ser avaliado conforme a rentabilidade; e qual a posição competitiva relativa de uma empresa dentro de um segmento de negócio. 
Já o modelo das competências essenciais de Hamel e Prahalad (1990) traz como diferencial a análise interna da organização. Por sua vez, o modelo de Coutinho e Ferraz (1995); Ferraz, Kupfer e Haguenauer (1995) considera as análises interna, externa e setorial dos fatores determinantes da competitividade empresarial, como uma evolução mais completa.

\subsection{O modelo dos fatores determinantes da competitividade: Coutinho e Ferraz (1995); e Ferraz, Kupfer e Haguenauer (1995)}

Abordando com mais ênfase o modelo de Coutinho e Ferraz (1995); e Ferraz, Kupfer e Haguenauer (1995), pode-se verificar que esse modelo, por meio do conceito de competitividade, fundamentado em uma análise mais completa dos fatores que determinam a competitividade empresarial, possibilita a percepção, simultânea, dos processos internos da organização e as situações econômicas gerais do ambiente produtivo, admitindo que se inclua um cenário pronto e ativo da competitividade.

De acordo com Coutinho e Ferraz (1995, p.19), "o desempenho competitivo de uma empresa, indústria ou nação é condicionado por um vasto conjunto de fatores, que pode ser subdividido naqueles internos à empresa, nos de natureza estrutural, pertencentes aos setores industriais, e nos de natureza sistêmica". Para Silva (2004) e Coutinho e Ferraz (1995), os fatores que formam a competitividade de uma empresa são:

a) Fatores determinantes empresariais ou internos: são os fatores que estão diretamente ligados à ação da organização. Definem seu potencial para obter a permanência e concorrem no mercado. Também estão efetivamente sob o domínio da empresa e dizem respeito a sua capacidade de gerenciar o negócio, a inovação, os processos, a informação, as pessoas e o relacionamento com os clientes;

b) Fatores determinantes estruturais ou setoriais: constituem-se no desenvolvimento e na estruturação da oferta e demanda. São os fatores externos à organização, referindo-se especificamente ao mercado em que atua, onde a organização pode apenas interferir;

c) Fatores determinantes sistêmicos: estão relacionados ao ambiente macroeconômico, político, social, legal, internacional e à infraestrutura, sobre os quais a empresa pode apenas exercer influência.

A Figura 1 esboça o modelo inicial elaborado para o estudo, ao qual se ligam os fatores determinantes da competitividade. 


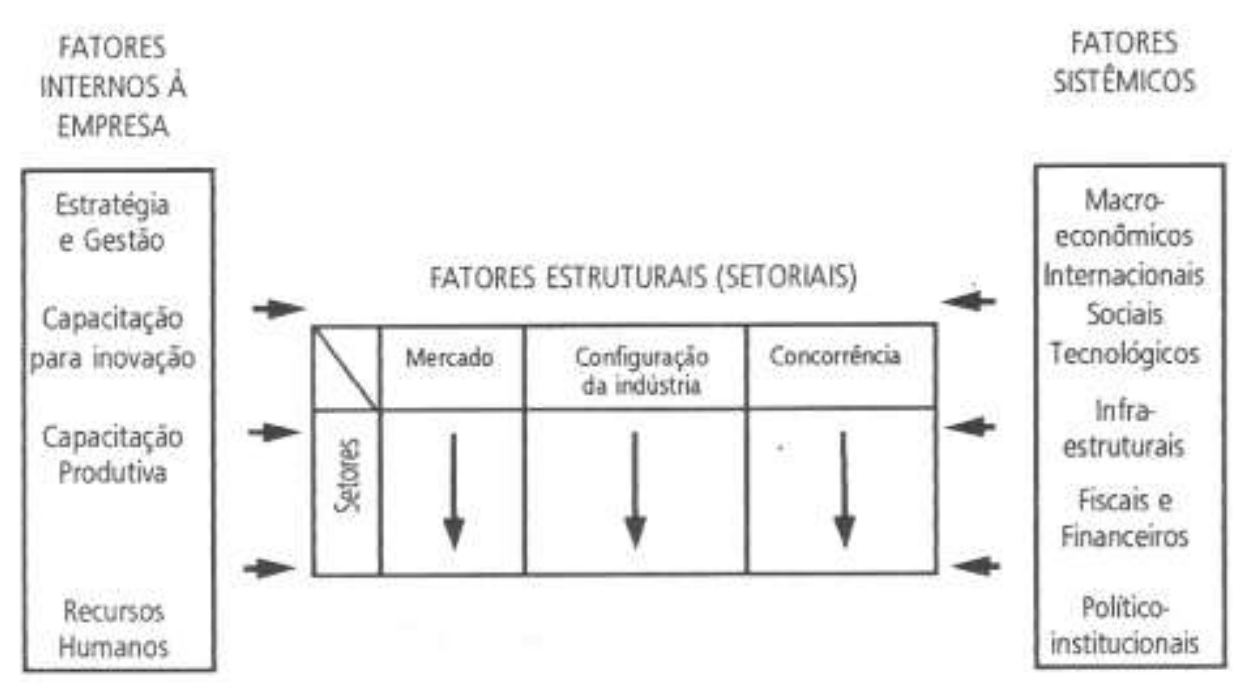

Figura 1. Fatores determinantes da competitividade da indústria Fonte: Coutinho e Ferraz, 1995, p. 19.

Os três fatores que dão forma à competitividade da empresa (internos, estruturais e sistêmicos) permitem a execução do estudo da competitividade empresarial. Conforme os autores Ferraz, Kupfer e Haguenauer (1995), os fatores empresariais e sistêmicos proporcionam um caráter mais genérico na forma e na intensidade com que influenciam a competitividade nos distintos setores. Já os fatores estruturais têm caráter setorial e específico, que refletem as peculiaridades dos padrões concorrenciais de cada ramo produtivo ou em grupo de setores similares.

\subsubsection{Fatores empresariais de competitividade}

São os fatores essenciais que dependem da maneira como a organização molda o seu processo de gestão, como considera seu mercado, seus concorrentes, o ambiente em que está introduzida a empresa e a sua visão do passado e futuro, ligando com seus alvos e metas, para sustentar-se ou ganhar parcela de mercado (SILVA, 2004). De acordo com Costenaro (2005), esses fatores se referem, fundamentalmente, ao estoque de recursos aglomerados pela empresa e às estratégias adotadas para o seu crescimento. Sendo assim, as estratégias são individuais de cada empresa e, por consequência, cada uma pode ter fatores distintos e maneiras alternativas de analisar o mesmo fato.

Os fatores empresariais são aqueles internos da organização, que Ferraz, Kupfer e Haguenauer (1995, p.10) descrevem como sendo "aqueles nos quais a organização detém poder de decisão e podem ser controlados através de procedimentos, correspondendo às variáveis no processo decisório". Tais fatores localizam-se no campo das decisões da empresa, que, por meio deles, busca distinguir-se de seus competidores (COUTINHO e FERRAZ, 1995).

Esses fatores relacionam-se a quatro áreas da competência de uma organização, que são: gestão, inovação, produção e recursos humanos. Os autores Ferraz, Kupfer, Haguenauer (1995) e Costenaro (2005) descrevem um a um: 
a) Gestão: é o processo de gestão que se refere ao comportamento da organização em relação às suas estratégias e aos padrões de concorrência. Dentro da gestão, incluem-se tarefas como: administrativas características da empresa, planejamento estratégico, finanças e marketing;

b) Inovação: é a capacidade de inovação que ocasiona resultados econômicos e também processos técnicos capaz de explorar as oportunidades para ocupar e criar mercados; está ligada também à capacidade da empresa em gerar inovações tecnológicas por meio de esforços de pesquisa e desenvolvimento de processos e produtos, além da transferência de tecnologia mediante licenciamento ou outras maneiras de intercâmbio tecnológico;

c) Produção: as atividades de produção relacionam-se ao depósito de recursos dirigidos no trabalho de manufatura, podendo conter referência tanto a equipamentos e instalações como aos artifícios de organização da produção e de controle de qualidade;

d) Recursos Humanos: as políticas de recursos humanos empregados numa organização são de grande importância para o sucesso da adoção de novas maneiras organizacionais. As ações exigidas para a administração de recursos humanos aplicam-se a muitos paradigmas que, no passado, eram reconhecidos como verdadeiros; por esse motivo, um significativo desenvolvimento se faz primordial para a sustentação das novas práticas desenvolvidas.

Para Silva (2004, p.49), as avaliações da empresa e dos fatores internos de competitividade "são exaustivas e complexas, não permitindo uma boa base de comparação entre as diferentes empresas de um determinado setor, que não seja a composição da participação do mercado, desde o seu histórico até as projeções para o futuro". Deste modo, o que se almeja com este estudo é identificar os métodos empresariais que ajudam na avaliação da decisão sobre práticas e ações adotadas por gestores do setor de pedras preciosas (COSTENARO, 2005).

\subsubsection{Fatores estruturais de competitividade}

Para Coutinho e Ferraz (1995, p.20), os fatores estruturais "são aqueles que, mesmo não sendo inteiramente controlados pela firma, estão parcialmente sob a sua área de influência e caracterizam o ambiente competitivo que ela enfrenta diretamente". Seguem no mesmo raciocínio Ferraz, Kupfer e Haguenauer (1995, p.10), afirmando que os fatores estruturais "são aqueles sobre os quais a capacidade de intervenção da empresa é limitada pela medição do processo de concorrência, estando por isso apenas parcialmente sob sua área de influência".

Dependendo do ambiente em que a organização se encontra, ela está mergulhada em uma estrutura de mercado que é privada do tipo de produto ou serviço com que ela compete (SILVA, 2004). O conjunto de fatores estruturais é formado por características dos mercados consumidores (demanda), como as características privadas da população que procura um determinado produto ou 
serviço; pela configuração da indústria (oferta), como os rivais e o tipo de estrutura, e pelas normas que determinam estruturas e comportamentos nas relações empresa-consumidor (COSTENARO, 2005).

A oferta, a demanda e as formas de regularização da concorrência compõem a estrutura de mercado. A Figura 3 ilustra 0 triângulo da competitividade estrutural (FERRAZ, KUPFER e HAGUENAUER, 1995; COUTINHO e FERRAZ, 1995; e COSTENARO, 2005), onde se podem conferir as inter-relações entre as características que fazem parte dos fatores determinantes estruturais. A seguir serão descritos os componentes do triângulo da competitividade.

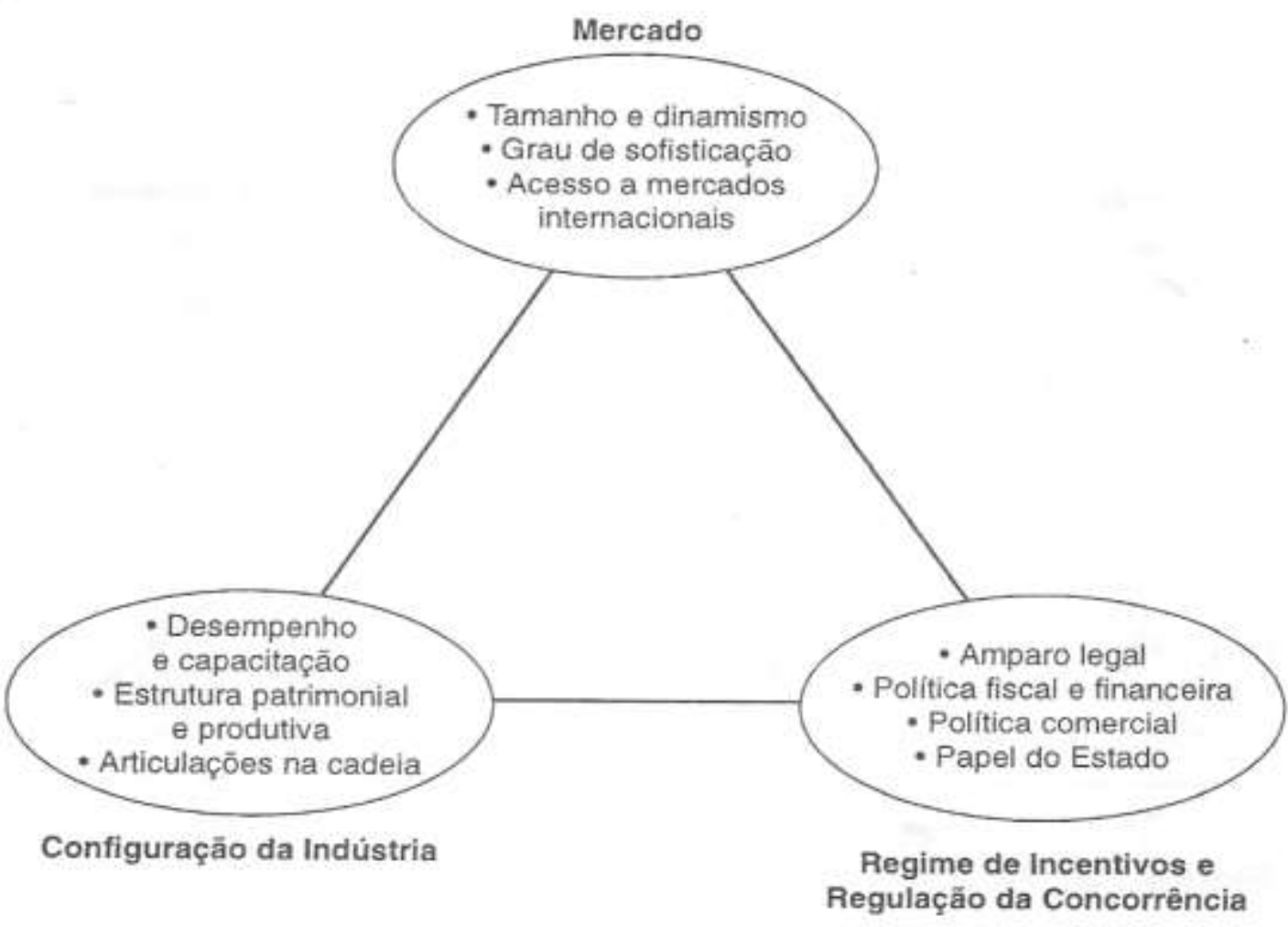

Figura 2. O triângulo da Competitividade Estrutural Fonte: Ferraz, Kupfer e Haguenauer, 1995, p. 12.

a) Mercado consumidor: a caracterização do mercado consumidor se dá em termos de sua distribuição geográfica e em faixas de renda, grau de sofisticação e outros requisitos impostos aos produtos; oportunidade de acesso a mercados internacionais; as formas e os custos de comercialização;

b) Configuração da indústria: a configuração da indústria em que a empresa atua é analisada através de características como grau de concentração de escalas de operação, atributos dos insumos, potencialidades de alianças com fornecedores, usuários e concorrentes, grau de verticalização e diversificação setorial e ritmo, origem e direção do progresso técnico; 
c) Concorrência: a concorrência é avaliada no que tange as regras que definem condutas e estruturas empresariais em suas relações com os consumidores, meio ambiente e competidores; o sistema fiscal - tributário incidente sobre as operações industriais, práticas de importações, exportações e a propriedades dos meios de produção.

Em contrapartida, Costenaro (2005) relata que a demanda é formada por fatores muito mais subjetivos que a oferta, porque depende do valor percebido de um conjunto de clientes sobre produtos e serviços para definir quanto eles estariam dispostos a pagar para o consumidor e de diferentes quantidades. Já a oferta está relacionada à indústria: um conjunto de produtores que compõem a oferta do produto, definem a configuração da indústria, exigida para atender à demanda. Na concorrência, as regras dão significado às condutas e estruturas empresariais e a suas relações com consumidores, meio ambiente e competidores (COSTENARO, 2005).

\subsubsection{Fatores sistêmicos de competitividade}

Além dos fatores empresariais e estruturais, a empresa está inserida e é influenciada pelo ambiente de competitividade, onde se depara com as forças externas sobre as quais a organização tem pequena ou quase nenhuma interferência e que desempenham poder de influência sobre a competitividade empresarial (COSTENARO, 2005).

Para Coutinho e Ferraz (1995, p.20), os fatores sistêmicos "são aqueles que constituem externalidade stricto sensu para a organização produtiva". Ferraz, Kupfer e Haguenauer (1995, p.12) completam: "sobre os quais a empresa detém escassa ou nenhuma possibilidade de intervir, constituindo parâmetros do processo decisório".

Para Coutinho e Ferraz (1995) e Ferraz, Kupfer e Haguenauer (1995), os fatores determinantes sistêmicos dividem-se quanto à natureza e são:

a) Macroeconômicos: taxa de câmbio, carga tributária, taxa de crescimento do produto interno, oferta de crédito e taxas de juros, política salarial e outros parâmetros;

b) Político-institucional: política tributária, política tarifária, apoio fiscal ou risco tecnológico, poder de compra do governo;

c) Legais-regulatórios: políticas de proteção à propriedade industrial, de preservação ambiental, de defesa da concorrência e proteção ao consumidor, de regulação do capital estrangeiro;

d) Infraestruturais: disponibilidade, qualidade e custo de energia, transportes, telecomunicação, insumos básicos e serviços tecnológicos (ciência e tecnologia; informação, tecnologia; serviços de engenharia, consultoria e projetos; metrologia e normalização e qualidade); 
e) Sociais: sistema de qualificação de mão de obra (educação profissionalizante e treinamento), políticas de educação e formação de recursos humanos, do trabalho e de seguridade social;

f) Internacionais: tendências do comércio mundial, fluxo internacional de capital, de investimentos de risco e de tecnologia, relação com organismos multilaterais, acordos internacionais.

Segundo Coutinho e Ferraz (1995), todos os itens que compõem o fator sistêmico, descritos acima, ajudam na avaliação da capacidade de formular e implementar estratégias; por isso, é importante verificar em que se fundamenta essa capacidade. Isso visa identificar os fatores condescendentes para o sucesso competitivo (empresariais, estruturais e sistêmicos), averiguar a sua importância setorial no atual e o que se pode aguardar no futuro próximo e considerar o potencial das empresas do país com relação a eles (COUTINHO e FERRAZ, 1995).

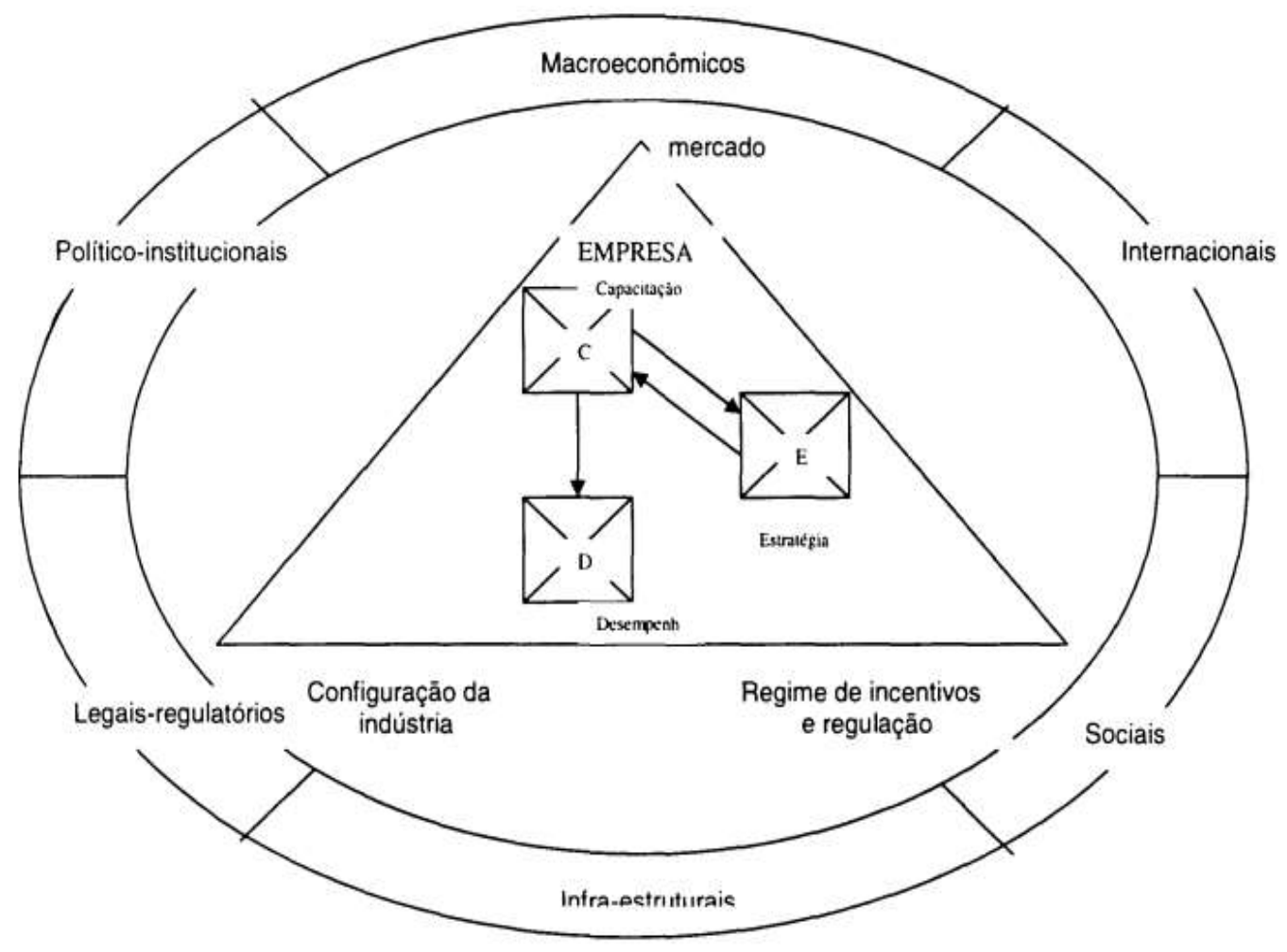

Figura 3. Fatores determinantes da competitividade Fonte: Ferraz, Kupfer e Haguenauer, 1995, p. 14.

A Figura 3 ilustra os três fatores que determinam a competitividade empresarial, estrutural e sistêmica. Ferraz, Kupfer e Haguenauer (1995, p.25) salientam o estudo dos diferentes fatores determinantes da competitividade e de seu desenvolvimento ao longo do tempo para situar a competitividade das organizações industriais no escopo econômico e no tempo, atrelando ao desenvolvimento da competitividade das organizações as modificações mais importantes do ambiente econômico que as rodeiam. 
Para Silva (2004, p.40), a compreensão dos fatores sistêmicos da competitividade "é um esforço de conhecer melhor o ambiente em que a empresa está inserida e este não é específico de um mercado, mas do local em que a empresa está localizada". Embasadas na compreensão dos conceitos e em uma visão dos fatores que determinam a competitividade que são os empresariais, estruturais e sistêmicos, as organizações podem conhecer melhor suas forças, as oportunidades e ameaças que as rodeiam, para delinear estratégias e ações práticas que deverão ser devidamente implementadas, e tenderão a somar as perspectivas de sobrevivência e de sucesso empresarial (COSTENARO, 2005).

\section{Método}

O método utilizado para atingir os objetivos gerais do presente trabalho é de cunho qualitativo-descritivo, sendo qualitativo por traduzir e expressar o sentido dos fenômenos do mundo social e descritivo por objetivar principalmente a descrição das características de uma população ou de um fenômeno, ou o relacionamento entre variáveis (GIL, 2002).

Este estudo configura-se como multicasos, que, segundo Triviños (1987), consiste em "estudar dois ou mais sujeitos, organizações [...] sem necessidade de perseguir objetivos de natureza comparativa", objetivando pesquisar quais os fatores competitivos do setor de pedras preciosas de Salto do Jacuí, especialmente no que se refere à etapa de análise.

A população da pesquisa é composta por todas as empresas do setor industrial pertencentes ao setor de pedras preciosas de Salto do Jacuí - RS, habilitadas e certificadas para desempenhar suas devidas funções. Salienta-se que há poucas empresas do setor no município devido à interdição do garimpo no ano de 2010. Muitas empresas que antes atuavam no município não tiveram condições financeiras para se ajustarem às normas exigidas. As empresas que compõem a amostra serão identificadas como empresa $A$, empresa $B$ e empresa $C$, tendo em vista questões de ética e sigilo. Por essa mesma razão, cabe destacar que não será apresentado nenhum dado que as caracterizem.

Todas as empresas da amostra atuam na extração das pedras preciosas, porém nem todas fazem o mesmo processo produtivo: algumas realizam apenas o corte ou beneficiamento das pedras, isoladamente.

Para a operacionalização da pesquisa, optou-se por tomar como base 0 modelo de Coutinho e Ferraz (1995); e Ferraz, Kupfer e Haguenauer (1995) por ser esse, dentre os estudados, o que mais se encaixa ao estudo do setor em análise e também por conter um modelo para se usar como embasamento, ou seja, o estudo de Costenaro (2005), principalmente por ser o mais atual da autora.

Costenaro (2005) aplicou o modelo dos fatores determinantes da competitividade no município de Soledade, onde se encontram várias empresas do setor e de segmentos diferenciados que trabalham com a pedra, como corte, tingimento, polimento e beneficiamento.

Assim, a técnica de coleta de dados foi entrevista semiestruturada, tendo como roteiro uma adaptação do instrumento de pesquisa de Costenaro (2005). O mesmo foi segmentado em três etapas, para maior objetividade e transparência: fatores empresariais, estruturais e sistêmicos, respectivamente. 
A utilização dessa técnica de coleta de dados justifica-se, pois, segundo Triviños (1987), "[...] favorece não só a descrição dos fenômenos sociais, mas também sua explicação e a compreensão de sua totalidade [...]". Nesse sentido, possibilita maior aprofundamento das questões estudadas.

As entrevistas foram realizadas pessoalmente após agendamento prévio com os gestores das empresas que compuseram a amostra. Na ocasião, foram gravadas e, posteriormente, transcritas na íntegra. A análise de conteúdo foi utilizada como técnica para explorar os dados obtidos, visando interpretar as mensagens e compreender seus significados (MORAES, 1999).

Os dados coletados foram analisados e descritos com o propósito de identificar aspectos comuns ou divergentes entre as empresas pesquisadas, gerando assim informações que permitam emoldurar a investigação dos objetivos estabelecidos.

\section{Análise dos resultados}

Neste capítulo será apresentada a análise das entrevistas, conforme a compreensão dos gestores do setor em estudo, de forma a identificar quais dos fatores - empresariais, estruturais, sistêmicos - desempenham maior influência na competitividade das empresas industriais de pedras preciosas de Salto do Jacuí RS. A análise foi dividida conforme os três fatores, que são: fatores empresariais, fatores estruturais e fatores sistêmicos.

\subsection{Fatores empresariais}

O primeiro fator em estudo é o empresarial. Fatores empresariais "são aqueles nos quais a organização detém poder de decisão e podem ser controlados através de procedimentos, correspondendo às variáveis no processo decisório" (FERRAZ, KUPFER, HAGUENAUER, 1995, p.10). Os fatores empresariais dividemse em quatro áreas de competências, as quais são: gestão, inovação, produção e recursos humanos.

Em relação ao tema venda, os gestores foram indagados a respeito da ordem em que ocorre: se primeiro a empresa produz para efetuar as vendas posteriormente ou vende para depois produzir. As respostas podem ser sintetizadas, conforme segue:

"A venda é feita de maneira diferenciada, em forma de leilão. Tenho um número $\mathrm{X}$ de clientes - compradores - quando fecho um lote de pedra, mando por e-mail para esses compradores, que decidem se irão comprar ou não". (Empresa B)

"Minha empresa trabalha da seguinte forma a venda de pedras, primeiramente faz a extração, a classificação e para depois exportá-las". (Empresa C)

"Tem todo um processo até que seja extraída a ágata, depois é feita a classificação para venda no mercado interno e externo". (Empresa A) 
Nesse quesito, todas as empresas demonstram partir da mesma estratégia de vendas, que é produzir, classificar o produto, para então buscar um público consumidor, seja ele nacional ou estrangeiro.

Verificou-se que cada empresa tem maneiras distintas de gerenciar seu negócio, devido, basicamente, aos pontos de vista divergentes dos gestores quanto ao próprio negócio, mercado, consumidores e ambiente onde está inserida sua empresa. O próprio processo de vendas, na descrição diferenciada dos gestores, está relacionado à gestão da empresa. Ferraz, Kupfer, Haguenauer (1995) definem gestão como sendo um processo, que se refere ao comportamento da organização em relação a suas estratégias e aos padrões de concorrência. Ele é composto por características estratégicas da empresa, planejamento estratégico, finanças e o marketing.

Em se tratando do planejamento estratégico, entende-se que atualmente as empresas devem ter a habilidade de avaliar o ambiente onde estão inseridas para que possam, assim, formular estratégias para alcançar os objetivos desejados. Ressaltou-se nos relatos dos gestores questões relacionadas a planejamento, projeções, objetivos e metas:

"O planejamento foi implantado na empresa quando eu assumi a gerência e fez toda a diferença. A empresa trabalha com projeções e metas em longo prazo". (Empresa C)

"Nós trabalhamos com projeções de custos, despesas e lucros que são avaliadas mensalmente. $E$ também trabalhamos com metas e objetivos anualmente". (Empresa B)

"Nós trabalhamos com metas, como por exemplo, de ampliação da produção, mas para que isso aconteça devemos investir em maquinários, equipamentos, colaboradores, entre outros. Já a produção é anualmente, é fechado o ano com uma produção X". (Empresa A)

Verifica-se que todas as empresas formulam e implantam o planejamento estratégico, cada uma de sua maneira. Segundo Ferraz, Kupfer e Haguenauer (1995), é a capacidade da organização de formular e implementar estratégias que permite ampliar ou conservar, de forma duradoura, uma posição sustentável no mercado. Mesmo o fato de as empresas da amostra continuarem suas atividades após outras terem saído do mercado (2010), pode estar associado à capacidade de planejar, com vistas a sustentar ou ampliar a posição que ocupa no mercado.

Continuando no mesmo tópico, no que se refere às estratégias, as empresas devem acompanhar as tendências de mercado, para que se atualizem e assim possam ter mais competitividade. Observa-se, nos relatos a seguir, como as organizações acompanham as tendências de mercado do setor de pedra preciosa:

"A empresa acompanha as tendências de mercado, sendo assim são os nossos compradores que criam tendências de mercado". (Empresa A)

"No setor de pedras, e em qualquer ramo de atividade, devemos sempre estar atentos às novas tendências de mercado, elas ditam moda". (Empresa B) 
Com base nos relatos, pode-se dizer que as empresas, de modo geral, acompanham as tendências de mercado e a inovação. $E$, conforme dito anteriormente, a inovação faz parte da área de competência da organização. Ferraz, Kupfer, Haguenauer (1995); e Costenaro (2005) relatam que é a capacidade de inovação que ocasiona resultados econômicos e também processos técnicos que possibilitam explorar as oportunidades para ocupar e criar mercado. Entende-se, assim, que dado o setor de atividade, as empresas têm de obrigatoriamente acompanhar as tendências de mercado para tornar seu produto atrativo aos consumidores.

Em relação aos recursos humanos da organização, quanto às quatro áreas de competência de uma empresa, ressalta-se nos relatos dos gestores como é formada a sua equipe de colaboradores e como desempenham suas atividades:

"Temos oito colaboradores e cada um com sua função específica, os mesmos tiveram noções básicas de técnicas de segurança do trabalho e saúde ocupacional no total de 40 horas. Temos também um técnico de segurança do trabalho responsável pela equipe". (Empresa A)

"Minha empresa conta com 64 colaboradores, e cada um com sua devida função. Dentro da empresa, como a equipe é grande, tem líder responsável por cada setor da empresa". (Empresa C)

"A empresa tem 15 colaboradores e todos têm sua determinada função, como, por exemplo, tem o encarregado do garimpo, a equipe que trabalha no escritório, o classificador, os operadores de maquinários e assim por diante". (Empresa B)

Por mais que haja diferença no número de colaboradores entre as empresas, percebe-se que os gestores definem as atividades e com isso têm as funções específicas, equipes com líderes para cada setor e oferecem treinamentos a seus colaboradores. Conforme Ferraz, Kupfer, Haguenauer (1995); e Costenaro (2005) relatam, os recursos humanos são empregados numa organização de acordo com sua política, que é de grande importância para o sucesso da adoção de novas maneiras organizacionais.

Observou-se, nos relatos dos gestores do setor de pedras preciosa do município, que cada gestor tem uma visão de sua empresa, de mercado, da concorrência e do ambiente onde as empresas estão colocadas. Sendo assim, o fator empresarial está no campo de decisão da empresa, que, por meio dele, busca distinguir-se de seus concorrentes (COUTINHO e FERRAZ, 1995). Segundo Silva (2004), os fatores empresariais dependem da maneira como a organização molda o seu processo de gestão, como considera seu mercado, seus concorrentes, o ambiente em que está introduzida a empresa e a sua visão de passado e futuro, ligando com seus alvos e metas, para sustentar-se ou ganhar parcela de mercado.

\subsection{Fatores estruturais}

Nessa segunda etapa serão apresentados os resultados da pesquisa, conforme a compreensão dos gestores, sobre os fatores estruturais, que são os fatores externos à organização, referindo-se especificamente a mercado em que 
atua, onde a organização pode apenas interferir (COUTINHO e FERRAZ, 1995, p.10). Os fatores estruturais se dividem em três componentes, que são: mercado consumidor, configuração da indústria e a concorrência.

No que diz respeito à participação ou intenção de a empresa participar de algum tipo de feira ou evento, podem ser examinados os relatos abaixo:

"Até hoje não, mas tenho planos para o próximo ano e participar da maior feira de exposição de pedras preciosas". (Empresa B)

"A minha empresa não participa de nenhum evento, pois são muitas despesas e gastos, e a meu ver não dão o retorno que valha a pena investir". (Empresa C)

"Não participamos até o momento, mas pretendemos participar, não como expositores, mas como observadores". (Empresa A)

Ressalta-se que uma das empresas tem uma visão diferenciada referente a eventos e feiras deste segmento. As outras têm uma visão mais a longo prazo, pois as mesmas compreendem que, participando de eventos e feiras, mesmo que seja como participante, no primeiro momento irão averiguar como se comporta a concorrência e também podendo obter conhecimento de novos mercados. Eventos e feiras configuram o mercado consumidor. Ferraz, Kupfer e Haguenauer, (1995); Coutinho e Ferraz, (1995) relatam que são as características do mercado consumidor em termos de sua distribuição geográfica e em faixas de renda, grau de sofisticação e outros requisitos impostos aos produtos; oportunidade de acesso a mercados internacionais; as formas e os custos de comercialização.

Observa-se nos relatos a seguir, em relação às práticas de exportações e aos entraves burocráticos, o seguinte:

\footnotetext{
Para minha empresa, a exportação funciona da seguinte forma, é extraído o produto, feito a nota e encaminhado até o porto e então é recebida a chamada carta dinheiro, exportação tem muitos benefícios para a empresa. (Empresa C)

Os trâmites para exportação são bem simples, para mim que trabalho há anos. Há vários benefícios e também malefícios, um deles é a oscilação do dólar, porque se vendo a um preço e o dólar sobe, terei mais lucro; mas em contrapartida, se o dólar cai, ganharia menos. (Empresa B)
}

Até há pouco tempo atrás a empresa trabalhava com a exportação, mas depois da interdição do garimpo, optamos por fazer uma venda para o mercado nacional, para conseguir tirar a empresa do vermelho. Os entraves burocráticos são muitos, pagamos até uma taxa de inseticida. (Empresa A)

Em relação à exportação, não se tem muito que diferenciar de uma empresa para outra, pois a forma de exportação é igual para todas. Algumas (Empresa A), porém, por motivos desconhecidos, encontram mais entraves, os quais a fizeram desistir da atividade de exportação. Todos os gestores relatam os trâmites para exportar, os quais afetam a competitividade. A exportação se encaixa na 
concorrência, segundo Ferraz, Kupfer e Haguenauer, (1995); e Coutinho e Ferraz, (1995), que tange as regras que definem conduta e estrutura empresarial em suas relações com consumidores, meio ambiente e competidores; o sistema fiscaltributário incidente sobre as operações industriais; práticas de importações, exportações e a propriedades dos meios de produção.

Atualmente, para alguns setores e até mesmo para as empresas de pequeno e médio porte, é válido fazer alianças ou participar de alguma cooperativa. Em relação ao assunto se a empresa faz parte, ou pretende participar de alianças ou cooperativas, observa-se nos relatos dos gestores:

"Não faria parte nem pretendo fazer, porque são muitas pessoas para trabalhar e às vezes não tem o mesmo pensamento". (Empresa B)

"Não faria parte de cooperativas, alianças, acredito que não cabem no ramo de extração e mineração de pedras". (Empresa A)

"A empresa está em um porte muito elevado, não tem a necessidade de fazer alianças ou participar de cooperativas". (Empresa C)

Observa-se que todas as empresas têm a mesma visão sobre as alianças e cooperativas, ou seja, não fariam parte desse tipo de relacionamento. Como principais motivos, os gestores afirmaram que as cooperativas ou alianças têm políticas distintas da forma de gestão que desenvolvem em suas empresas; e há a troca de diretoria de tempos em tempos e isso acarreta em uma gestão de interesse distinto, pois cada gestor tem sua maneira de administrar e visualizar a mesma situação. Ferraz, Kupfer e Haguenauer, (1995); Coutinho e Ferraz, (1995); e Costenaro, (2005) expõem que a configuração da indústria em que a empresa atua é avaliada por grau de concentração de escalas de operação, atributos dos insumos, potencialidades de alianças com fornecedores, usuários e concorrentes, grau de verticalização e diversificação setorial e ritmo, origem e direção do progresso técnico.

Entende-se que, dadas as peculiaridades citadas pelos entrevistados, a participação em relacionamentos interorganizacionais poderia ser favorável principalmente para o amadurecimento das empresas como um todo. Conforme relatos, cada uma tem pontos fortes e fracos diferentes, que poderiam ser otimizados através de trocas de informações. Pesämaa e Hair (2007) citam que parcerias entre empresas podem gerar desenvolvimento da legitimidade e aumento da reputação das empresas, maior facilidade de obter financiamentos, compartilhar e complementar recursos e competências e Provan e Kenis (2008) consideram ainda o atendimento mais eficaz de clientes, a atração de recursos e resolução de problemas complexos, o que vai ao encontro de maior competitividade e participação de mercado.

A respeito da terceirização presente no setor de pedras preciosas, pode-se afirmar que duas das empresas contratam algum tipo de serviço terceirizado, como para exportações, mão de obra e mecânica para os caminhões. Já uma das empresas não trabalha com a contratação de serviço terceirizado, mas sim com locação, conforme reforçado pelos relatos abaixo: 
"A empresa trabalha com o serviço terceirizado de explosões, é contratada uma empresa que se localiza fora do município para alcançar os devidos fins". (Empresa B)

"A minha empresa trabalha com a mão de obra terceirizada, mas dependendo da época de extração, e também a parte mecânica dos caminhões é de serviço terceirizado". (Empresa C)

"Não trabalhamos com terceirização, mas sim com locação de equipamentos e funcionários". (Empresa A)

Segundo os relatos dos gestores do setor de pedras do município em estudo, em relação a esses conjuntos de fatores, os gestores podem apenas interferir. Reforçando esse entendimento, Costenaro (2005) afirma que o conjunto de fatores estruturais é formado por características dos mercados consumidores (demanda), como as características privadas da população que procura um determinado produto ou serviço; pela configuração da indústria (oferta), como os rivais e o tipo de estrutura, e pelas normas que determinam estruturas e comportamentos em suas relações empresa-consumidor. Conforme Silva (2004), dependendo do ambiente em que a organização encontra-se, ela está mergulhada em uma estrutura de mercado que é privada ao tipo de produto ou de serviço com que ela compete.

\subsection{Fatores sistêmicos}

Nesta terceira etapa do presente trabalho será apresentada a análise, segundo a compreensão dos gestores, a respeito dos fatores sistêmicos, que estão relacionados ao ambiente macroeconômico, político, social, legal, internacional e à infraestrutura, sobre os quais a empresa pode apenas exercer influência (FERRAZ, KUPFER e HAGUENAUER, 1995, p12). Os fatores sistêmicos dividem-se, quanto à natureza, em: macroeconômicos, político- institucional, legais-regulatórios, infraestrutura, sociais, internacionais, os quais serão tratados a seguir.

Nos relatos dos gestores abaixo, pode ser observado como o dólar afeta a competitividade da empresa.

"O dólar afeta a competitividade da empresa, mas as taxas de câmbio afetam mais". (Empresa B)

"O dólar afeta muito a competitividade da empresa porque temos uma receita $X$ por mês e, caso o dólar baixe cinco centavos, por exemplo, afeta muito o resultado esperado". (Empresa $A$ )

“Depende muito de que momento é efetuada a venda, quando o dólar está em alta ou baixa, porque às vezes conseguimos fechar um lote bom, mas às vezes um ruim, mas faz parte do funcionamento de uma empresa". (Empresa C)

Avalia-se que, para as empresas, o dólar tem seu lado bom, mas também seu lado ruim, mas, como se pode observar, a taxa de câmbio afeta mais que o dólar. Salienta-se que, mesmo não tendo controle sobre esses valores, a análise do ambiente macroeconômico pode melhorar as taxas de sucesso das negociações. No fator sistêmico, o macroeconômico é composto por taxa de câmbio, carga tributária, taxa de crescimento do produto interno, oferta de créditos e taxas de 
juros, política salarial e outros parâmetros, todos esses se configuram de natureza macroeconômica (FERRAZ, KUPFER e HAGUENAUER, 1995).

Seguindo nesse mesmo raciocínio, os gestores foram questionados quanto às mudanças, caso o governo diminuísse a carga tributária, conforme segue:

\begin{abstract}
Caso houvesse uma diminuição na carga tributária, haveria vários benefícios, como uma geração de caixa maior para enfrentarmos momentos turbulentos como o que passamos. A economia não é uma linha estável, ela tem altos e baixos e isso afeta as empresas. Ela tem que criar gordura para enfrentar momentos de "vacas magras", e pelo fato também que pode gerar mais recursos, investir e gerar mais riquezas; aumento da produçã̃o, colocação de mais funcionários.

(Empresa A)
\end{abstract}

"Se houvesse uma diminuição na carga tributária, seria muito bom, pois as empresas iriam contratar mais funcionários e iriam investir bem mais". (Empresa B)

"Para as empresas de grande porte seria muito bom se houvesse uma diminuição da carga tributária, mas em contrapartida iria abrir muitas empresas de pequeno porte e isso não seria bom". (Empresa C)

Esses relatos também podem se configurar de natureza política, pois são divididos em: política tributária, política tarifária, apoio fiscal ou risco tecnológico, poder de compra do governo. Observou-se que todos os gestores têm a mesma opinião sobre o tema, que seria muito bom caso isso ocorresse, mas também haveria algumas desvantagens, como abertura de mais empresas, visto que acarretaria mais concorrência. Visualiza-se, desse modo, uma abordagem reduzida dos efeitos que causaria a diminuição da carga tributária. Se, para esses gestores, o aumento do número de empresas é prejudicial, em termos de mercado, a concorrência estimula melhorias do setor que vêm ao encontro de novas demandas.

Quando questionados quanto à disponibilidade de mão de obra qualificada no município, os gestores responderam conforme segue:

"Em nosso município não existe mão de obra". (Empresa B)

"Atualmente não há, nem há um tempo atrás quando havia mais garimpos". (Empresa C)

"A contratação de mão de obra qualificada é bem difícil". (Empresa A)

Verificou-se que no município em estudo, não há mão de obra qualificada para o setor de extração de pedras, visto o problema que as empresas têm em relação à contração de mão de obra qualificada. Conforme descrito no referencial teórico, o fator sistêmico divide-se quanto à sua natureza social divide-se: sistema de qualificação de mão de obra (educação profissionalizante e treinamento); políticas de educação e formação de recursos humanos; trabalhistas; e de seguridade social. Nesse quesito, dada a importância do município no setor de pedras preciosas, a falta de mão de obra qualificada pode acarretar problemas ainda não vislumbrados, tais como a diminuição forçada da produção. Nesse 
sentido, políticas empresariais ou mesmo governamentais que estimulassem a qualificação da mão de obra local viriam prevenir futuras perdas e contribuir para o avanço do setor.

Analisou-se, com os relatos dos gestores do setor de pedras do município em estudo, que as empresas procuram uma melhor maneira de gerir a empresa, porque os fatores sistêmicos são os que influenciam na competitividade das empresas. Segundo Silva (2004), o ambiente, onde a organização atua, exerce força externa na definição econômica, fiscal e financeira, social, política e institucional, legal ou regulatória, internacional e tecnológica. A concepção dos fatores sistêmicos é conhecer bem o ambiente em que a empresa está colocada, e esses não são específicos de um mercado, mas o local em que a organização está inserida (SILVA, 2004).

\section{Considerações Finais}

O presente trabalho teve como objetivo geral verificar e descrever os fatores que influenciam a competitividade das empresas industriais pertencentes ao setor de pedras preciosas em Salto do Jacuí - RS, a partir da compreensão dos seus gestores, segundo o modelo proposto por Coutinho e Ferraz (1995); e Ferraz, Kupfer e Haguenauer (1995).

Para tanto, buscou-se primeiramente embasar o estudo com teorias encontradas na literatura no que tange à competitividade e ao setor de pedras preciosas no contexto brasileiro, do estado do Rio Grande do Sul e, por fim, município em estudo, Salto do Jacuí.

No que se refere à competitividade, verificou-se que existem várias linhas de pensamento, que auxiliam no aprofundamento dos conhecimentos sobre o tema do presente trabalho. Dada essa diversidade, a competitividade foi estabelecida no trabalho como sendo a aptidão das empresas em conservar ou amplificar, de maneira a perdurar, uma colocação sustentável no mercado, consequência da gestão dos fatores empresariais, estruturais e sistêmicos.

Em relação a Salto do Jacuí, esse município é referência por possuir uma das maiores jazidas de pedras ágatas do mundo. No título que o município levava, houve uma modificação devido à interdição do garimpo (2010), havendo uma redução no número de empresas do setor em estudo e também de outros ramos de atividades. Isso afetou todo o comércio do município, pois antes havia mais de 500 trabalhadores direta ou indiretamente ligados ao garimpo de extração de pedras ágatas e atualmente o número de trabalhadores nesse setor reduziu muito no município.

Dadas as evidências da literatura, foi desenvolvido um estudo de multicaso, entrevistando três empresas do setor de extração de pedras. Assim, foi possível identificar os fatores empresariais, estruturais e sistêmicos que influenciam a competitividade das empresas industriais de pedras preciosas de Salto do Jacuí RS. Pode-se averiguar que este mercado em estudo mostra variadas propriedades privadas, cujo conhecimento constitui uma das questões-chave para o sucesso das organizações. 
Conclui-se que, dos fatores empresariais, estruturais e sistêmicos, o que apresenta maior influência na competitividade das empresas industriais pertencentes ao setor de pedras preciosas de Salto do Jacuí é o fator sistêmico (macroeconômico, político-institucional, legal-regulatório, de infraestrutura, social e internacional). Esse fato se justifica pela incapacidade de os gestores dominarem os componentes do fator sistêmico, o que torna a atuação das empresas mais limitada. Além disso, dado o modelo de autores Coutinho e Ferraz (1995); e Ferraz, Kupfer e Haguenauer (1995), esses fatores acabam por afetar os demais e, nesse sentido, mesmo as definições empresariais mais consagradas podem sofrer alterações compulsórias por exigências de alterações nos fatores sistêmicos. Nesse sentido, a continuidade das empresas no mercado, ou mesmo o aumento da participação, requer uma contínua análise dos três fatores para adequações progressivas que vão sendo observadas.

Em relação aos fatores empresariais e estruturais, chegou-se à seguinte conclusão: os gestores têm condições de administrar conforme as necessidades de suas empresas dadas as características de gestão desenvolvidas. Notou-se que as empresas já atuam no mercado há algum tempo, o que proporciona um conhecimento empírico do funcionamento diferenciado. Porém, nem por isso os gestores deixam de buscar novas práticas de gestão, o que influencia nas evidências positivas dos fatores empresariais e estruturais, sobre os quais a empresa exerce domínio ou influência. Ainda, entende-se que a busca e troca de conhecimentos com outras empresas do setor poderia agregar valor aos produtos e serviços, possibilitando também que questões comuns fossem sanadas com maior efetividade, havendo crescimento para todas. Mesmo os problemas relativos à mão de obra poderiam ser minimizados por meio de parcerias, ao se fazer investimentos conjuntos para a capacitação dos colaboradores.

Dada uma das limitações deste estudo, que foi a coleta de dados unicamente por entrevistas, sugere-se que, para estudos futuros, sejam consideradas outras formas de coleta, tais como a observação das rotinas das empresas. Esse método possibilitaria uma melhor visualização de como são paliçadas as afirmações dos gestores e como impactam nas atividades diárias.

Sugere-se ainda a elaboração de estudos em empresas de lapidação e beneficiamento, pois neste trabalho analisou-se só um setor, o de extração de pedras. Além disso, conforme exposto no referencial teórico, existem outros modelos de competitividade, os quais também poderiam ser aplicados no setor em análise.

\section{REFERÊNCIAS}

COSTENARO, Alessandra. Indústria de Pedras Preciosas: um estudo dos fatores competitivos em empresas de Soledade - RS. 96 f. Dissertação (Programa de Pós-Graduação em Administração) - Universidade Federal de Santa Maria, Santa Maria, 2005. 
COUTINHO, Luciano; FERRAZ, João C. Estudos da Competitividade da Indústria Brasileira. 3.ed. Campinas: Papiro, 1995.

FERRAZ, João C; KUPFER, Devid; HAGUENAUER, Lia. Made In Brasil: desafios competitivos para a indústria. 2. ed. Rio de Janeiro: Campus, 1997/1996.

GIL, Carlos Antonio. Métodos e Técnicas de Pesquisa Social. 5.ed. São Paulo: Atlas 1999.

Como elaborar projetos de pesquisa. 4.ed. São Paulo: Atlas, 2002.

HAMEL, Gay; PRAHALAD, C.H. Competindo pelo Futuro: estratégia inovadora para obter o controle do seu setor e criar os mercados de amanhã. Rio de Janeiro: Campos, 1990.

MACHADO, Cátia dos Reis. Análise estratégica baseada em processos de inteligência competitiva (IC) e gestão do conhecimento (GC): proposta de um modelo. Tese doutorado. Universidade Federal de Santa Catarina. Florianópolis, 2010.

MARCONI, Andrade Marina de; LAKATOS, Maria Eva. Fundamento de Metodologia Cientifica. 5.ed. São Paulo: Atlas. 2003.

MORAES, R. Análise de Conteúdo. Revista Educação, Porto Alegre, v.22 n.37, 1999.

PESÄMAA, O.; HAIR, J. F. More than friendship is required: an empirical text of cooperative firm strategies. Management Decision, v. 45, n. 3, p. 602-615, 2007.

PORTER, Michael E. Estratégia Competitiva: Técnicas para análise de indústria e da concorrência. 7.ed. Rio de Janeiro: Campus. 1986.

. Vantagem competitiva das nações. Rio de Janeiro: Campus, 1989.

.Competição - on competition: estratégias competitivas essenciais. 6. ed. Rio de Janeiro: Campus, 1999.

PROVAN, K. G.; KENIS, P. Modes of Network Governance: Structure, Management, and Effectiveness. Journal of Public Administration Research and Theory, v. 18, p. 229-252, 2008.

SILVA, Christian Luiz da. Competitividade na Cadeia de Valor: um modelo econômico para tomada de decisão empresarial. 2.ed. Curitiba: Juruá, 2004.

TRIVIÑOS, A. N.S. Introdução à pesquisa em ciências sociais: a pesquisa qualitativa em educação. 1.ed. São Paulo: Atlas, 1987. 
YIN, Robert K. Estudo de caso: planejamento e métodos. 2. ed. Porto Alegre: Bookman, 2001.

Submetido em 24/01/2012

Aprovado em 16/06/2014

\section{Sobre os autores}

Juliano Nunes Alves

Doutorando em Administração pela Universidade Federal de Santa Maria, Santa Maria, RS e

Doutorando Visitante em Marketing na Universidade de Turku, Turku, Finlândia.

Professor e Coordenador do Curso de Administração na Universidade de Cruz Alta, Cruz Alta, RS.

Endereço Av. Voluntários da Pátria, 968. CEP 98025-770 - Cruz Alta - RS - Brasil.

E-mail:admjuliano@yahoo.com.br.

\section{Josiane Lamaison de Moraes}

Graduada em Administração pela Universidade de Cruz Alta - Unicruz.

Endereço: Cristo Rei no 117 - Bairro: São Cristóvão. CEP: 95320-000 - Nova Prata - RS - Brasil.

E-mail: jozi_lamaizon@hotmail.com

\section{Denise Rossato Quatrin}

Mestranda em Administração, na área de Sistemas, Estruturas e Pessoas, na Universidade Federal de Santa Maria,

Endereço: Rua Venancio Aires, 1269. apto 302. CEP 97010-001 - Santa Maria - RS - Brasil.

E-mail: dequatrin@gmail.com 